\title{
Effect of Urine Extract on Leucocyte Peroxidase. An Early Laboratory Finding of Avitaminosis B.
}

58th Report of the Peroxidase Reaction.

$\mathrm{By}$

Tamotsu Suzuki and Akira Takamatsu.

（鈴木保）(高松舀)

(From the Department of Pediatrics, Faculty of Medi-

cine, Tohoku Imperial University, Sendai.

Director: Prof. A. Sato.)

In a preceding paper ${ }^{1)}$ (57th Report of the Peroxidase Reaction) Suzuki, one of the authors, has made an investigation into the relation between the urine of mothers with human milk negative to Arakaw a's reaction and the prolongation of the shortest proxidase staintime of normal blood neutrophiles, in other words, into the relation between the urine from a $\mathrm{B}$-avitaminotic body and the prolonging effect of the B-avitaminotic urine. And he has found out that an application of the urine from lactants with A raka wa-negative milk causes a prolongation of the shortest peroxidase stain-time of normal blood neutrophiles from a normal person. On the contrary, the urine from mothers with Arakawa-positive milk will not, as he has found out, cause any prolongation at all.

Now we ${ }^{2}$ know already that an A rakawa-negative milk, that is, milk from a $\mathrm{B}$-avitaminotic body causes the prolongation in question, while no prolongation will occur with an A rak a w a-positive milk. And we know further that, as Takamatsu, ${ }^{3)}$ one of us, has been able to isolate a methyl glyoxal-like substance from human milk negative to Arakawa's reaction, an ether extract of the Arakawa-negative milk will cause the prolongation in question. And synthesized methyl glyoxal itself does the same thing, as our experiment ${ }^{23}$ has shown.

1) T. Suzuki, Tohoku J. Exp. Med., 1935, 25, 575.

2) T. Suzuki and Takamatsn, Tohoku J. Exp. Med., 1934, 24, 202.

3) T. Tak a matsu, Tohoku J. Exp. Med., 1934, 23, 46. 
Then it will be quite natural to think that an ether extract of the urine from a mother with A rak a w a-negative milk may prolong the shortest peroxidase stain-time of normal blood neutrophiles, while that of the urine from a mother with Arak a wa-positive milk will not, as will be thought, cause the prolongation in question. We desire to report on the actual result in the present paper.

\section{Method of Experiment.}

Materials: 1. Urine was obtained from almost all the mothers of the breast-fed patients who visited our dispensary. Milk was examined with Arakawa's reagent in each case. To collect the whole one-day urine may be ideal, but it was impossible, because only fresh urine would answer the purpose.

2. Ether extract of urine: Urine was treated with ether. Ether was evaporated and an aqueous solution of the extracted substance was prepared. One portion of the extract was used to estimate the concentration of the methyl glyoxal-like substance in the urine; the other portion was used for blood specimens. In the experiment in Table II the urine freed from the ether extract was also used for blood specimens.

3. Normal blood specimens: Blood films were obtained from healthy persons and neutrophiles were tested with the shortest peroxidase stain-time; in individuals with no B-deficit it should, as Su$\mathrm{zuki}^{4}{ }^{4)}$ one of the authors, has shown, be two seconds (in human cases).

Technique: Blood films were covered with urine, ether urine extract or urine freed from ether extract for about ten seconds, and then the technique of Sato-Sekiya-Suzuki, as described in K.Suzuki's ${ }^{57}$ and T. Suzuki's ${ }^{4)}$ papers, was used.

Identification of methyl glyoxal-like substance: To the prepared extract water was added and distilled at $100^{\circ} \mathrm{C}$. The fraction was a clear liquid and had a characteristic odour suggesting the presence of methyl glyoxal. And the fraction showed iodoform reaction on the addition of iodine potassium iodate and reduced the Fehling's solution and ammoniacal silver solution. It formed osazone with, p-nitrophenyl hydrazine. Besides, the influence of the substance on A ra$\mathrm{k}$ aw a's reaction was very much like that of methyl glyoxal. We made a determination of methyl glyoxal by means of converting methyl gly-

4) T. Suzuki, Tohoku J. Exp. Med., 1934, 23, 23.

5) K. Suzuki, Tohoku J. Exp. Med., 1932, 19, 262. 
oxal into iodoform as F. Fischer and R. Boethner $r^{6}$ had experienced (Cf. Taka mats u's ${ }^{3)}$ report for further details).

\section{Result of Experiment.}

If one glances at Table I, one will recognize a remarkable parallelism between the A rakaw a reaction of human milk of a given mother and the prolonging effect of her urine. In general, a mother whose Arakawa's reaction is normal excretes a urine which will not cause the prolongation in question, while the urine of a mother whose Arakawa's reaction is very weak will prolong remarkably the shortest peroxidase stain-time of blood neutrophiles. No. 1 in Table I with Arakawa's reaction (H) 1 ' shows no prolongation of the normal shortest peroxidase stain-time (=2 seconds), while in No. 31 with A.R. $(-) 5^{\prime}$ the prolongation is 7 seconds $\left(=9^{\prime \prime}-2^{\prime \prime}\right)$.

But this fact is what Suzuki, one of the authors, has already shown is a preceding paper ${ }^{1)}$ of urine with a larger number of cases. What we want to show here properly, is that the prolonging factor of the urine is extractable with ether, because the time of prolongation caused by a urine coincides precisely or almost precisely with that caused by its extract. From such a urine as has not caused any prolongation no prolonging substance is extracted (Nos. 1 and 2 in Table I for instance); while an ether extract from a urine with a remarkable prolonging effect will cause a remarkable prolongation (Nos. 30 and 31 in Table I for instance).

Furthermore, if one compares in Table I the length of time of prolongation caused by a urine and the amount of the methyl glyoxal-like substance in the ether extract of the urine, one will recognize that there is a close relation between them, so that the ether extract of the urine of No. 1. (Cf. Table I) with no prolongation contains no methyl glyoxal-like substance, that the extract of the urine of No. 20 with the prolongation $3^{\prime \prime}\left(=\overline{0}^{\prime \prime}-2^{\prime \prime}\right)$ contain almost 1 mgrms. \% of the substance and that the extract of the urine of No. 31 with the prolongation $7^{\prime \prime}$ $\left(=9^{\prime \prime}-2^{\prime \prime}\right)$ contains about 2.9 mgrms. $\%$ of the substance.

From the above statements, it is clear that, if the urine of a given case causes a prolongation of the shortest peroxidase stain-time, then its ether extract will cause the same or almost the same grade of prolongation and its prolonging effect is due to a methyl glyoxal-like substance contained in it.

6) F. Fischer and R. B oet hner, Ztschr. analyt. Chem., 1928, 74, 28. 
Effect of Urine Extract on Leucocyte Peroxidase

\begin{tabular}{|c|c|c|c|c|c|c|c|c|}
\hline \multirow{9}{*}{ 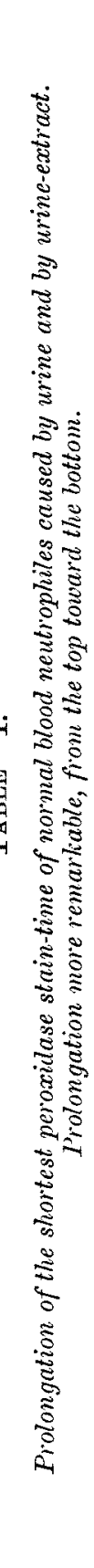 } & \multirow{2}{*}{\multicolumn{2}{|c|}{ 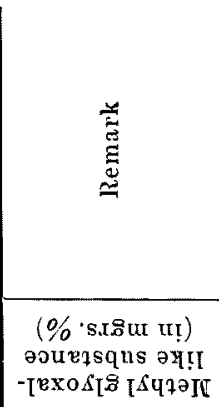 }} & \multicolumn{2}{|c|}{ 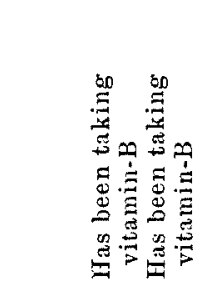 } & 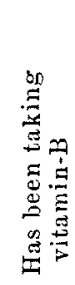 & \multicolumn{2}{|c|}{ 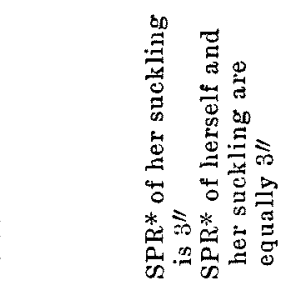 } & 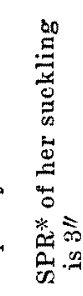 \\
\hline & & & 0000 & 0 & 85 & 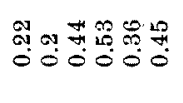 & $\begin{array}{l}\infty \\
\infty \\
0 \\
0\end{array}$ & $\begin{array}{l}\infty \\
\infty \\
\infty \\
0\end{array}$ \\
\hline & 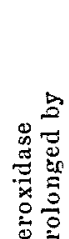 & 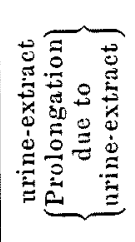 & 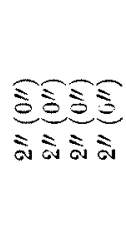 & $\begin{array}{c}\hat{\delta} \\
\bar{\delta}\end{array}$ & 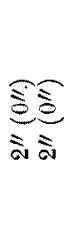 & 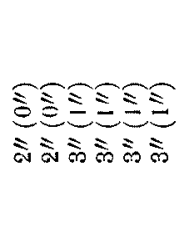 & $\stackrel{5}{10}$ & $\begin{array}{l}\widehat{E}= \\
\text { is = }\end{array}$ \\
\hline & 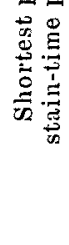 & 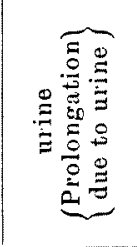 & 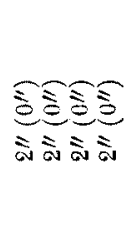 & $\begin{array}{c}\text { อิ } \\
\text { సे }\end{array}$ & डิ & 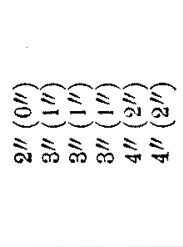 & $\underset{\vdots}{\vdots}$ & 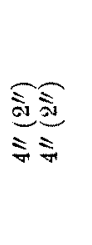 \\
\hline & 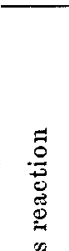 & 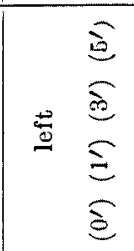 & 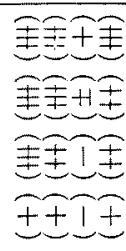 & $\begin{array}{l} \pm \\
\pm \\
\pm \\
\pm \\
\pm \\
\pm\end{array}$ & 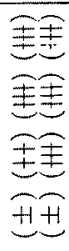 & 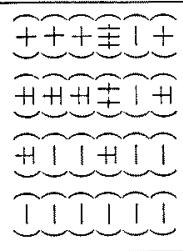 & $\begin{array}{l}I \\
\pm \\
\pm \\
I \\
I \\
I\end{array}$ & $\begin{array}{l}\text { II } \\
\pm I \\
\pm I \\
\pm I \\
\text { II } \\
\text { II }\end{array}$ \\
\hline & 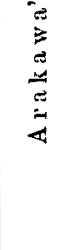 & 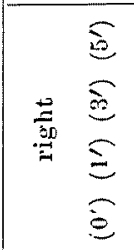 & 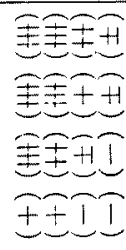 & $\begin{array}{l}I \\
\pm \\
\pm \\
\pm \\
\pm \\
\pm\end{array}$ & 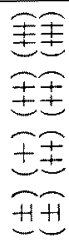 & 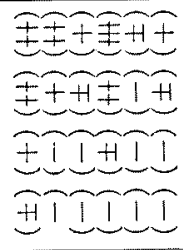 & $\begin{array}{l}I \\
I \\
I \\
I \\
I \\
I\end{array}$ & $\begin{array}{l}T I \\
T I \\
I I \\
I I \\
\frac{I I}{I I}\end{array}$ \\
\hline & & 00 & 芯态䍐点 & $\overrightarrow{\text { N }}$ & $\overrightarrow{\sigma o s}$ & 恶嵒芯品 & $\stackrel{\infty}{\infty}$ & 920 \\
\hline & & $\stackrel{\stackrel{0}{E}}{\stackrel{E}{Z}}$ & ن & Ë & 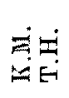 & 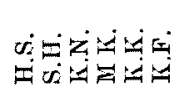 & 远 & ن \\
\hline & & 总家 & $-\infty \infty \pi$ & $\infty$ & $\phi r$ & $\infty \circ \varrho=心 \cong$ & $\Xi$ & $\mathscr{2}=$ \\
\hline
\end{tabular}




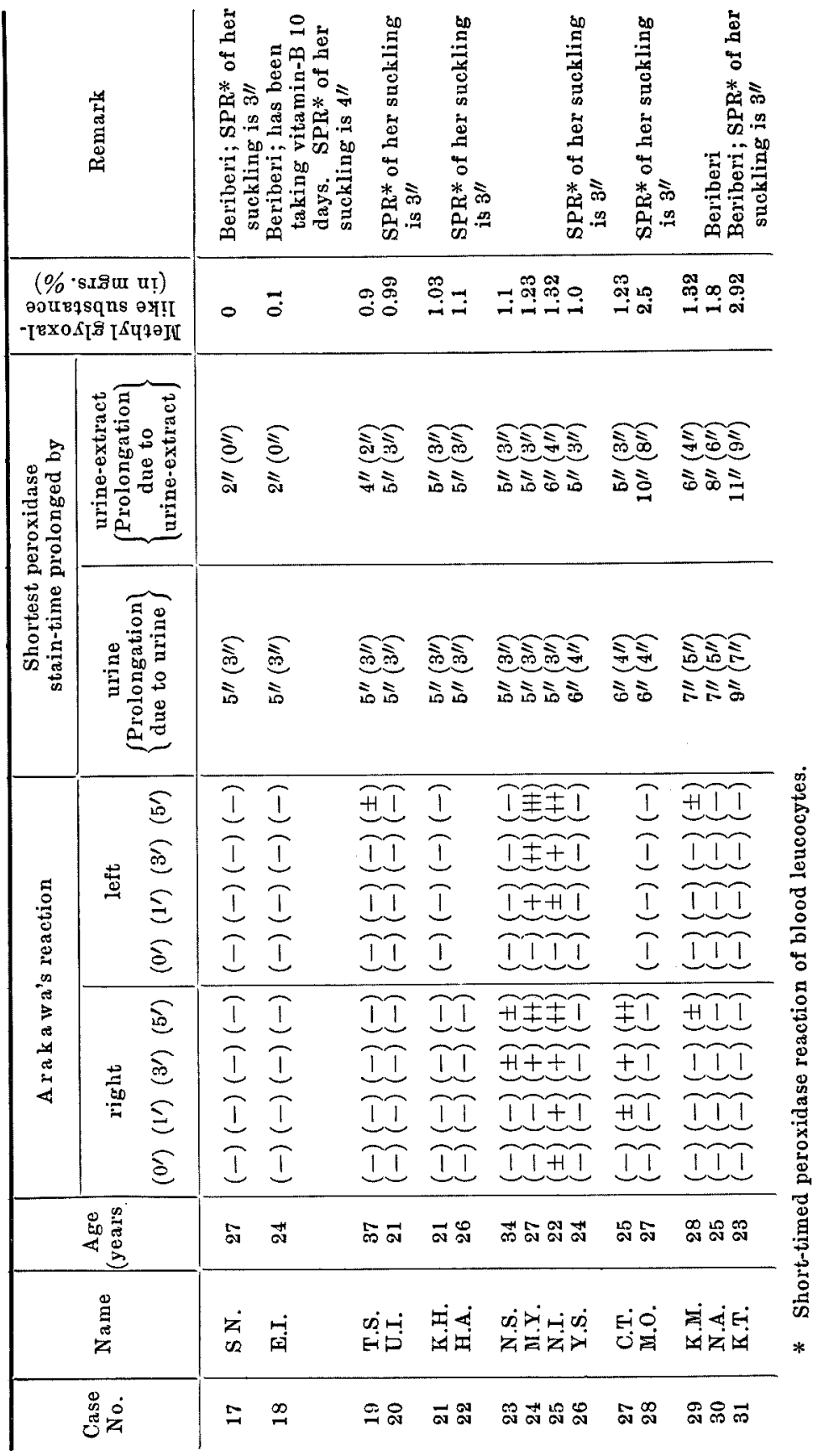


Some remarks should be made about Nos. 17 and 18 in Table $I$, because these two cases form an exception to the above rule. We think that there must have been some experimental error or other, especially in the technique of the extraction of the urine. Besides, there is a possibility of reducing the prolonging poison of the urine by an administration of vitamin $\mathrm{B}$, though this is a problem to be solved in the future.

\section{Further Result of the Experiment \\ (Cf. Table II).}

In the preceding paragraph, we have shown that the prolonging factor of a urine is extractable with ether. Then it must follow that the urine freed from the prolonging factorwould not exercise any prolonging effect on the shortest peroxidase staintime on blood neutrophile leucocytes. The result given in Table II is the proof. Even the prolonging factor of a urine with a prolongation of 5 seconds $\left(=7^{\prime \prime}-2^{\prime \prime}\right)$ was extracted exhaustively (Cf. No. 1 in

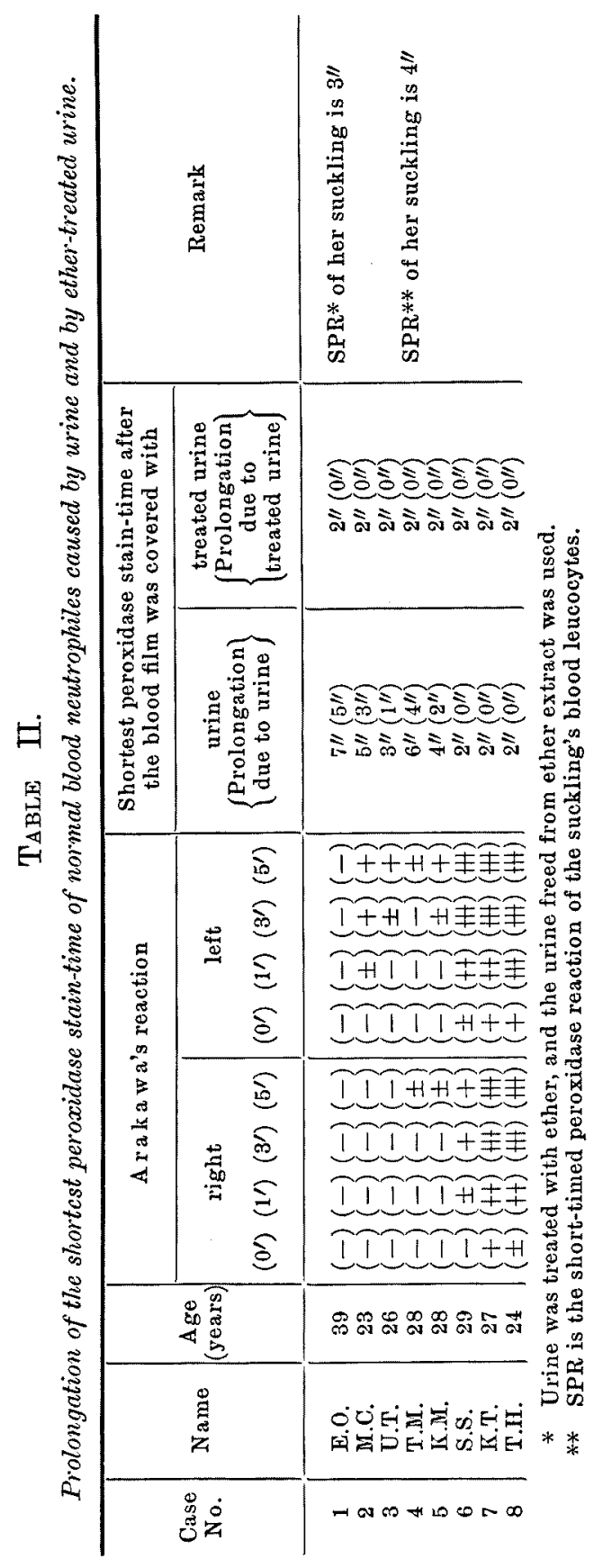


Table II), because no further prolonging effect was seen in the ether treated urine. And from such a urine as from No. 8, which had no prolonging effect, no extract possessed of prolonging effect resulted.

Then it is clear that the prolonging factor of the urine is exhaustibly extractable with ether, and that the ether extract represents all the prolonging effect of the urine, so that the ether treated urine does not possess a prolonging effect any longer.

\section{Comment.}

A mother with human milk negative to Arakawa's reaction excretes a urine which will cause a prolongation of the shortest peroxidase stain-time of normal blood leucocytes from a normal person. This is not the case with a mother whose human milk is normally positive to Arakawa's reaction. This is what has been shown in a preceding paper. $^{1)}$

Now to what is the prolonging effect of the urine of a B-avitaminotic mother due? The prolonging factor of a urine with the prolonging effect is exhaustively extractable with ether, so that the ethertreated urine has lost its prolonging effect and the ether extract represents the whole prolonging factor. And a methyl glyoxal-like substance which has been extracted from human milk negative to A ra$\mathrm{kaw}$ a's reaction is again identified in a urine with a prolonging effect. And generally the amount of the substance is proportional to the effect of the prolongation. From a urine of a mother with Arakawapositive milk such a substance is not identified.

Now, a human milk negative to Arakawa's reaction is, as has been repeatedly shown by a number of papers from our Laboratory, a milk from a B-avitaminotic body. Such a milk has a prolonging effect on the shortest peroxidase stain-time of normal blood leucocytes from a normal person, ${ }^{2)}$ and a methyl glyoxal-like substance is identified in such a milk. ${ }^{23)}$ Now the urine from a B-avitaminotic lactant mother has a prolonging effect and a methyl glyoxal-like substance has, as the present paper shows, been identified from such a urine. Then we can say with reason that a B-avitaminotic mother excretes a B-avitaminotically poisonous urine, especially if the work of Ro senberg and $\mathrm{Geiger} \mathrm{r}^{7)}$ and of Taka matsu $\mathrm{u}^{3}$ are taken into consideration.

And therefore it is possible to presume also in a non-lactant mo-

7) A. Geiger and A. Rosenberg, Klin. Wschr., 1933, 1258. 
ther or even in a man a state of avitamonosis B on the basis of a prolonging effect of her or his urine. Only it is too hasty to conclude that, though a non-B-avitaminotic mother excretes a urine with no prolonging effect, a lactant excreting a urine which will cause no prolongation is free from avitaminosis $\mathrm{B}$, especially if the case has been taking vitamin $\mathrm{B}$. The prolonging substance may possibly disappear by this medication before the case is wholly recovered from a state of $\mathrm{B}$-avitaminosis.

\section{Conclusions.}

1. Ether extract of the urine of a lactant with negative Arakawa's reaction causes, like that urine itself, a prolongation of the normal shortest peroxidase stain-time of normal blood neutrophiles. This is not the case with the urine of a lactant with A rak a wa-positive milk.

2. The urine which causes the prolongation in question, if treated with ether, no longer has the prolonging effect.

3. The prolongation in question manifested by a urine is roughly proportional to the amount of a methyl glyoxal-like substance identified in that urine.

4. A urine from an apparently " healthy" lactant which causes the prolongation in question is from a B-avitaminotic body. 